This item was submitted to Loughborough's Research Repository by the author.

Items in Figshare are protected by copyright, with all rights reserved, unless otherwise indicated.

\title{
Effect of prolonged walking with backpack loads on trunk muscle activity and fatigue in children
}

PLEASE CITE THE PUBLISHED VERSION

http://dx.doi.org/10.1016/j.jelekin.2007.06.013

PUBLISHER

(C) Elsevier

VERSION

AM (Accepted Manuscript)

\section{PUBLISHER STATEMENT}

This work is made available according to the conditions of the Creative Commons Attribution-NonCommercialNoDerivatives 4.0 International (CC BY-NC-ND 4.0) licence. Full details of this licence are available at: https://creativecommons.org/licenses/by-nc-nd/4.0/

\section{LICENCE}

CC BY-NC-ND 4.0

\section{REPOSITORY RECORD}

Hong, Youlian, Jing-Xian Li, and Daniel Tik-Pui Fong. 2019. "Effect of Prolonged Walking with Backpack Loads on Trunk Muscle Activity and Fatigue in Children". figshare. https://hdl.handle.net/2134/21246. 
Elsevier Editorial System(tm) for Journal of Electromyography and Kinesiology

Manuscript Draft

Manuscript Number:

Title: Electromyography patterns of trapezius muscles and rectus abdominis during prolonged walking on treadmill with different backpack loads in 6-year-old children

Article Type: Research Paper

Keywords: Muscle activity; muscle fatigue; schoolbag; load carriage

Corresponding Author: Prof Youlian Hong, PhD

Corresponding Author's Institution: The Chinese University of Hong Kong

First Author: Youlian Hong, PhD

Order of Authors: Youlian Hong, PhD; Jing-Xian Li, PhD; Daniel Tik-Pui Fong, MSc

Abstract: This study investigated the electromyography patterns of shoulder and abdominal muscles during prolonged walking with loads in children. Fifteen Chinese children aged six performed four 20-minute walking trials on treadmill (speed $=1.1 \mathrm{~ms}-1)$ with different backpack loads $(0 \%, 10 \%, 15 \%$ and $20 \%$ bodyweight). Electromyography signals from upper trapezius (UT), lower trapezius (LT) and rectus abdominis (RA) were recorded at time intervals $(0,5,10,15$ and 20 minutes), and were normalized to the signals collected during maximum voluntary contraction. Integrated EMG signal (IEMG) was calculated to evaluate the muscle activity. Power spectral frequency analysis was applied to evaluate muscle fatigue by the shift of median power frequency (MPF). Overall results showed that $15 \%$ and $20 \%$ loads increased IEMG at UT and both UT and LT respectively. In prolonged walking, $15 \%$ and $20 \%$ loads increased IEMG at UT from 15 and 5 minutes respectively. With a $20 \%$ load, muscle fatigue was found at UT from 10 minutes and at LT from 15 minutes. No muscle activity changes or muscle fatigue was found in RA. It is suggested that a load within $15 \%$ of the body weight in a backpack was acceptable to children aged six for walking within 20 minutes. 
This study investigated the electromyography patterns of shoulder and abdominal muscles during prolonged walking with loads in children. Fifteen Chinese children aged six performed four 20-minute walking trials on treadmill $\left(\right.$ speed $\left.=1.1 \mathrm{~ms}^{-1}\right)$ with different backpack loads $(0 \%, 10 \%, 15 \%$ and $20 \%$ bodyweight). Electromyography signals from upper trapezius (UT), lower trapezius $(L T)$ and rectus abdominis $(R A)$ were recorded at time intervals $(0,5$, 10, 15 and 20 minutes), and were normalized to the signals collected during maximum voluntary contraction. Integrated EMG signal (IEMG) was calculated to evaluate the muscle activity. Power spectral frequency analysis was applied to evaluate muscle fatigue by the shift of median power frequency (MPF). Overall results showed that $15 \%$ and $20 \%$ loads increased IEMG at UT and both UT and LT respectively. In prolonged walking, $15 \%$ and $20 \%$ loads increased IEMG at UT from 15 and 5 minutes respectively. With a $20 \%$ load, muscle fatigue was found at UT from 10 minutes and at LT from 15 minutes. No muscle activity changes or muscle fatigue was found in RA. It is suggested that a load within $15 \%$ of the body weight in a backpack was acceptable to children aged six for walking within 20 minutes. 


\section{CONFLICT OF INTEREST STATEMENT}

Ref: submission of the paper titled "Electromyography patterns of trapezius muscles and rectus abdominis during prolonged walking on treadmill with different backpack loads in 6-year-old children"

We declare no conflict of interest includ ing employment, consultancies, stock ownership, honoraria, paid expert testimony, patent application/registrations, and grants or other funding.

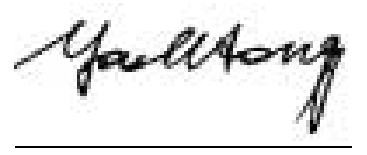

Youlian Hong

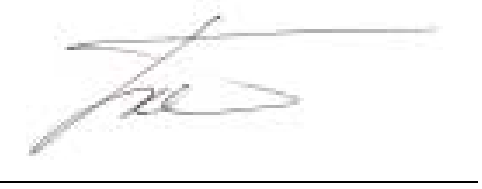

Jing-Xian Li

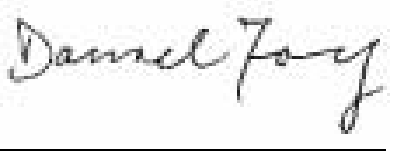

Daniel Tik-Pui Fong

15 January 2007 
Dear Editor of Jo urnal of Electromyoraphy and Kinesiology,

Ref: submission of the paper titled "Electromyography patterns of trapezius muscles and rectus abdominis during prolonged walking on treadmill with different backpack loads in 6-year-old children"

We would like to submit the captioned manuscript to the Journal of Electromyography and Kinesiology, Elsevier. All authors have read and approved the content of this manuscript as submitted. This manuscript has not been published and will not be simultaneously submitted to other journals.

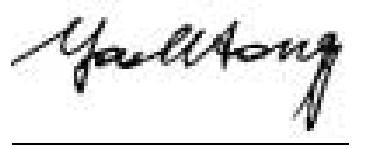

Youlian Hong

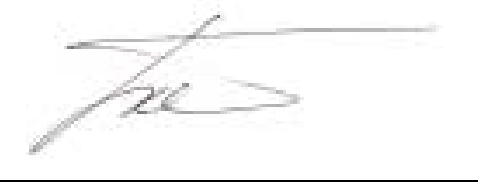

Jing-Xian Li

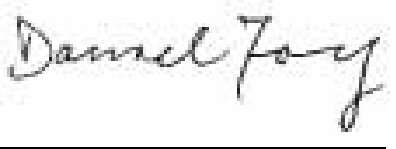

Daniel Tik-Pui Fong

15 January 2007 
Title

Affiliation

Keywords

Corresponding

author

Telephone

Email
Electromyography patterns of trapezius muscles and rectus abdominis during prolonged walking on treadmill with different backpack loads in 6-year-old children

Youlian HONG ${ }^{1}$, Jing-Xian LI ${ }^{1,2}$, Daniel Tik-Pui FONG ${ }^{1,3}$

${ }^{1}$ Department of Sports Science and Physical Education, Faculty of Education; The Chinese University of Hong Kong, Hong Kong, China.

${ }^{2}$ School of Human Kinetics, Faculty of Health Science, University of Ottawa, Ottawa, Ontario, Canada.

${ }^{3}$ Department of Orthopaedics and Traumatology, Prince of Wales Hospital, Faculty of Medicine, The Chinese University of Hong Kong, Hong Kong, China.

Muscle activity, muscle fatigue, schoolbag, load carriage

Youlian HONG,

Department of Sports Science and Physical Education, Faculty of Education, The Chinese University of Hong Kong, Hong Kong, China (852) 26096082

Facsimile

(852) 26035781

youlianhong@cuhk.edu.hk 
7 This study investigated the electromyography patterns of shoulder and abdominal

\section{Electromyography patterns of trapezius muscles and rectus abdominis during} prolonged walking on treadmill with different backpack loads in 6-year-old

\author{
children
}

\section{Abstract:}

muscles during prolonged walking with loads in children. Fifteen Chinese children aged six performed four 20-minute walking trials on treadmill (speed $=1.1 \mathrm{~ms}^{-1}$ ) with different backpack loads (0\%,10\%,15\% and $20 \%$ bodyweight). Electromyography signals from upper trapezius (UT), lower trapezius (LT) and rectus abdominis (RA) were recorded at time intervals $(0,5,10,15$ and 20 minutes), and were normalized to the signals collected during maximum voluntary contraction. Integrated EMG signal (IEMG) was calculated to evaluate the muscle activity. Power spectral frequency analysis was applied to evaluate muscle fatigue by the shift of median power frequency (MPF). Overall results showed that $15 \%$ and $20 \%$ loads increased IEMG at UT and both UT and LT respectively. In prolonged walking, $15 \%$ and $20 \%$ loads increased IEMG at UT from 15 and 5 minutes respectively. With a $20 \%$ load, muscle fatigue was found at UT from 10 minutes and at LT from 15 minutes. No muscle 
activity changes or muscle fatigue was found in RA. It is suggested that a load within

$21 \quad 15 \%$ of the body weight in a backpack was acceptable to children aged six for walking

22 within 20 minutes.

\section{Introduction:}

26 Concerns have been raised over recent decades about the backpack or school bag

27 weight of children in worldwide countries. The heavy weight of school bad has been 28 reported as $17.7 \%$ in the United States (Pascoe et al., 1997), 20\% in Italy (Negrini and 29 Carabalona, 2002) and $20 \%$ in Hong Kong (Hong Kong Society for Child Health and

30 Development, 1988). In Italy, Negrini and Carabalona (2002) reported that among 115

31 children aged 11.7 years old surveyed, $79.1 \%$ felt that they backpacks were heavy,

$3265.7 \%$ reported that the backpack introduced fatigue to them, and $46.1 \%$ developed

33 back pain from daily backpack carriage. In Hong Kong, the Hong Kong Society for

34 Child Health and Development (1988) reported that 45 out of 812 (5.5\%) surveyed 35 children had spinal deformity. The mean weight of their school bags was found to be 36 higher than the mean of the school bag weight of all 812 children. In 61 children 37 investigated in Pascoe's study (1997), the most commonly reported symptoms 38 included muscle soreness (67.2\%), back pain $(50.8 \%)$, numbness $(24.5 \%)$ and 
39 shoulder pain (14.7\%). In investigating the risk factors, Grimmer et al (1999) found

40 significant strong association between overweight backpacks and spinal symptoms. In

41 addition, Sheir-Neiss et al reported (2003) that heavy use of backpacks was

42 independently associated with back pain. Therefore, orthopaedics and biomechanics

43 specialists believed that habitual heavy backpack loads carriage may cause spinal

44 symptoms, low back pain and musculoskeletal disorder.

46 However, the cause-and-effect relationships between heavy backpack load and the

47 related syndromes can hardly be established by these prospective cohort studies

48 alone. Therefore, biomechanists and physiologists worked on different randomized

49 controlled trials to help understanding the effect and mechanism introduced by load

50 carriage. The oldest documented study was a physiology study conducted in 1965 in

51 India, which investigated the metabolic cost of carrying book bags weighing $2.6 \mathrm{~kg}$ on

52 six school boys aged from 9 to 15 years old (Malhotra and Sen Gupta, 1965). In 1977,

53 Voll and Klimt (1977) reported the common weight of school bags ( $11.1 \%$ to $14.3 \%)$

54 and the common distances the children walked to school (28.5 minutes), which served

55 as references for future researchers to determine representative loads and testing

56 time in experiment. After that, numerous biomechanics and physiology studies

57 emerged to reveal the effects of load carriage on energy expenditure (Hong et al., 
2000), cardiorespiratory response ( $\mathrm{Li}$ et al., 2003), lung volume and ventilation

59 restriction (Lai and Jones, 2001), gait kinetics (Hong and Li, 2005), trunk posture

60 (Chansirinukor et al., 2001), and gait kinematics (Kinoshita, 1985). Various settings of

61 load carriage were studies, including the position of load placement (Bobet and

62 Norman, 1984, Cook and Neumann, 1987), weight of loads (Johnson et al., 1995),

63 carrying method (Hong et al., 2003), walking speed (Charteris, 1998), age difference

64 (Li and Hong, 2004), level walking (Hong and Cheung, 2003) and stair walking (Hong

65 and $\mathrm{Li}, 2005)$. These studies in general suggested that a load of $15 \%$ bodyweight

66 triggered significant trunk inclination (Li and Hong, 2004), gait alternation (Hong and

67 Brueggemann, 2000), prolonged blood pressure recovery time (Hong et al., 2000),

68 larger energy expenditure (Hong et al., 2000), increased ventilation frequency (Li et

69 al., 2003), as well as moments and power at hip, knee and ankle joints (Chow et al., 70 2005).

72 While numerous studies on load carriage on children were found, none of them 73 reported the effect on muscle fatigue. In lower extremity, muscle fatigue leads to 74 postural control and balance impairment (Gribble and Hertel, 2004). In trunk and 75 upper extremity, muscle fatigue has significant effect in decreasing shoulder 76 proprioception (Carpenter et al., 1998) and hampered glenohumeral proprioception 
77 (Voight et al., 1996). As Pascoe et al (1997) mentioned that the reported symptoms

78 from load carriage in children included muscle soreness (67.2\%) and also shoulder

79 pain (14.7\%), it is necessary to have some investigations on shoulder muscle fatigue.

80 Trapezius muscles were selected as they were found to be sensitive to the changes of

81 load carriage in backpack (Bobet and Norman, 1982). Moreover, backpackers often

82 reported fatigue and soreness in trapezius muscles (Bjelle et al., 1981). Rectus

83 abdominis, which was located anterior to the human trunk, was a representative of

84 trunk flexor muscle. As Cook and Neumann (1987) reported that the lumbar

85 paraspinal muscles were less activated when a load was added posterior to the body,

86 and were more activated when a load was added anterior, it is expected that the

87 antagonistic muscles in the trunk should be activated in a reverse way to compensate.

88 When loads are added posterior to the human body, it is expected that the rectus

89 abdominis might play an important role to bring the body back to an upright position.

90 Previous study showed that abdominis muscle was found significant to contribute in

91 spine stabilization, and a delayed onset of abdominis contraction results in a lack of

92 control of trunk muscles and develops low back pain (Hodges and Richardson, 1996).

93 Muscle fatigue in abdominis may also result in a lack of control of trunk muscle.

94 Therefore this muscle is also selected. In this study, the effect of prolonged load

95 carriage in walking on muscle activity and fatigue in children was investigated. The 
main effects investigated included the loads and the time of walking.

97

2. Method:

99

$100 \quad$ 2.1. Subjects

101

102 Fifteen Chinese male children (Age $=6$ years) participated in this study. The subjects

103 were recruited from local primary schools. They used to carry two-strap backpack to

104 school daily. An orthopaedics physician examined all subjects to ensure that they

105 were free of musculoskeletal injury and pain before each trial. The procedures of the

106 whole experiment were introduced to the subjects and their parents before the test.

107 Informed consents from the subjects and their parents were obtained. The university

108 ethics committee approved the study.

109

110 Subjects were asked to come to the laboratory on four different days. There were a

111 total of four trials with different backpack loads for each subject. In each testing day,

112 each subject performed one trial in the morning. Before the trial, the subjects were

113 requested not to participate in any physical activities which may introduce tiredness.

114 The order of the trials was randomized for each subject. 
118 Before each trial, the subject was requested to wear black and tight shorts and no

119 shirt. Disposable silver/silver chloride preamplified bipolar surface electrodes

120 (Medicotest T-00-S, Denmark) were attached to upper trapezius (UT), lower trapezius

121 (LT) and rectus abdominis (RA) (Figure 1). All electrodes were placed on the right side

122 of the body. The electrode location was in the midline of the muscle belly between the

123 nearest innervation zone and the myotendinuous junction as suggested by De Luca

124 (De Luca, 1997), and was located and marked on the skin with ink by an orthopaedics

125 physician. A common ground electrode was attached to the anterior aspect of the

126 articular capsule of the sternoclavicular joint. Before electrode attachment, the skin

127 surface was slightly abraded with sandpaper and wiped with rubbing alcohol to

128 facilitate better attachment with reduced skin-electrode impedance (Boone and Holder,

129 1996). In each trial, new electrodes were attached again on the ink mark.

$131 \quad$ Maximum voluntary isometric contraction test

133 After the preparation of electrodes, a maximum voluntary isometric contraction test 
134 followed, which act as a reference to reflect the percentage of muscle contraction

135 performance capacity (Yang and Winter, 1984) for later comparison within subject.

136 Each subject was instructed to perform maximum voluntary contraction (MVC) on the

137 selected muscles. Firstly, the subject was instructed to stand up and perform

138 maximum shoulder elevation, while the shoulder motion was restricted by depression

139 force on both shoulders provided by two adult research assistants to ensure an

140 isometric muscle contraction at upper and lower trapezius. Secondly, the subject was

141 instructed to lie supine on the floor, and perform upward and forward trunk flexion.

142 The trunk flexion motion was again restricted by two adult research assistants by

143 applying downward forces at both shoulders to ensure an isometric muscle

144 contraction at rectus abdominis.

145

146 Each MVC test trial lasted for 10 seconds. During each trial, loud, strong and

147 continuous verbal encouragement was initiated by the same research staff, in order to

148 reduce the limitation of muscle contraction capacity by lack of motivation and

149 inhibitory effects (Vollestad, 1997). Three trials of shoulder elevation and three trials of

150 trunk flexion were performed, with a 3-minute rest in between each trial. The MVC test

151 was done before each of the four walking trials for all subjects to reduce the effect

152 introduced by new electrodes, by different testing day and time, and perhaps by 
153 slightly different electrode attachment locations.

154

Treadmill walking test

156

157 After the MVC test, subject was asked to take a 30-minute rest to remove any muscle

158 fatigue. The resting time was to ensure the subject did not feel jaded prior to the

159 treadmill walking test. All subjects reported that they did not feel fatigue after the rest

160 and did not require extra resting time. A two-strap backpack was prepared with the

161 testing load by filling with objects that students usually bring to school, such as books,

162 pencil box, sweater, water bottle, sports wear and shoes. The fillings were arranged

163 symmetrically inside the backpack. The four testing loads equaled $0 \%, 10 \%, 15 \%$ and

$16420 \%$ of the subject body weight. Percentage weight instead of absolute weight was

165 used to provide normalization across subjects.

166

167 The subject was allowed to practice walking on the treadmill without the testing

168 backpack until he felt familiar and secure. Then the subject put on the backpack and

169 performed a 20-minutes walking on treadmill with a speed of $1.1 \mathrm{~ms}^{-1}$. EMG signals

170 were collected during the walk at different time points $(0,5,10,15$ and 20 minutes).

171 The duration of the EMG signal collection at each time point is one minute. 
175 The electromyography (EMG) signals during MVC test and during treadmill walking

176 test were collected, amplified and transmitted by BTS EMG system (Bioengineering

177 Technology \& Systems, Italy) at $2000 \mathrm{~Hz}$ to a computer via a 12-bit A/D conversion

178 board (National Instruments, USA). LabView (National Instruments, USA) was used to

179 view and trim the collected EMG signals. For each MVC performance, five

180 two-second EMG samples were trimmed during the whole 60-second sample at the

181 position of $10,20,30,40$ and 50 seconds. All these five samples were processed to

182 obtain the mean value. This was to avoid the effect introduced by trimming at different

183 duration within the raw sample. For each load and each time point in the treadmill

184 walking test, the same data trimming procedure was employed.

186 BioProc EMG Data Processing System (University of Ottawa, Canada) was used to

187 process the trimmed EMG signals. Each trimmed signal was band-pass filtered

188 20-300 Hz, and was full-wave rectified. The filtered and rectified EMG signal was then

189 integrated (IEMG), and was normalized to the IEMG values of the corresponding

190 muscles recorded from the MVC test (\%MVC). The trimmed EMG signal was also 
191 filter again and was further processed for power spectrum analysis by Fourier

192 Transform method with $1000 \mathrm{~Hz}$ harmonics. Median power frequency (MPF) was

193 recorded to evaluate muscle fatigue. In quantifying muscle fatigue, researchers

194 investigated the drop of mean, median and mode of frequency spectrum. In this study,

195 median power frequency was used for muscle fatigue analysis as it is less sensitive to

196 noise and more sensitive to the biochemical and physiological processes that occur

197 within the muscles during sustained contraction (De Luca, 1997). Since the EMG

198 responses have a great degree of between-muscles, inter-individual and

199 intra-individual variation, the relative changes in the frequency were used for

200 comparison (Bobet and Norman, 1984). In demonstrating load effect, the MPF at 10\%,

$201 \quad 15 \%$ and $20 \%$ load were normalized to that at $0 \%$ load. In demonstrating the time

202 effect, the MPF at 5, 10, 15 and 20 min were normalized to that at $0 \mathrm{~min}$. A shift of

203 MPF of the EMG signal to the low end indicated muscle fatigue (De Luca, 1997).

204

$205 \quad$ Statistical analysis

206

207 Two-way multivariate analysis of variance (load by time) with repeated measures

208 (MANOVA) was applied on EMG patterns at all three selected muscles to see

209 significant effects by load and time. To determine load effect, ANOVA (Analysis of 
210 variance) and Tukey pairwise comparisons were conducted to determine any

211 significant changes on IEMG and MPF at each muscle. To determine time effect,

212 analysis was done at each load separately. ANOVA and Tukey pairwise comparison

213 was conducted between all selected time points at each load for both IEMG and MPF.

214 Statistical significance was set at 95\% level of confidence.

215

216 3. Results:

217

218 The integrated electromyography (IEMG) and the median power frequency (MPF) of

219 each muscle at each load and time point were shown in Figure 2 and Figure 3

220 respectively. MANOVA showed significant effects by both load (Wilk's lambda $=0.216$,

$221 \mathrm{~F}=2.206, \mathrm{p}=0.005)$ and time (Wilk's lambda $=0.159, \mathrm{~F}=2.794, \mathrm{p}=0.000$ ).

223 3.1 Load effect

224

225 As shown in Figure 2, there are increasing trends of IEMG with increasing load in

226 general. Significant increase in IEMG was found when the load was $20 \%$ in T1 ( $p$

$227<.05)$ and when the load was $15 \%$ and $20 \%$ in T4 $(p<.05)$. The load effect was not

228 significant in RA. For MPF, significant effect was found at $20 \%$ for both T1 and T4 ( $p$ 
$<.05)$, but not in RA.

230

231

3.2 Time effect

232

233 ANOVA showed that the time effect was significant in changes in IEMG in T4 and RA

$234(p<.05)$ but not T1 when load was not taken in account. Time effect was also

235 significant in introducing MPF changes in T1 and T4 $(p<.05)$ but not in RA. The time

236 effect was further evaluated at different load, and was represented in Figure 3 for

237 IEMG and in Figure 4 for MPF.

238

239 There were increasing trends of muscles activity with increasing walking time for all

240 muscles at all loads. When muscle activity (IEMG) was evaluated at different load, no

241 significant changes were found in T1 and RA. For T4, at 0\% load, IEMG significantly

242 increased from 4.5\% MVC at $0 \mathrm{~min}$ to $18.2 \% \mathrm{MVC}$ at $20 \mathrm{~min}(\mathrm{p}<.05)$. At $10 \%$ load, no

243 significant changes were found. At 15\% load, IEMG significantly increased from $7.1 \%$

244 MVC at 0 min to $22.3 \%$ MVC at $15 \min (p<.05)$ and to $25.8 \%$ MVC at $20 \min (p<.05)$

245 At $20 \%$ load, IEMG significantly increased from $4.3 \% \mathrm{MVC}$ at $0 \mathrm{~min}$ to $18.8 \% \mathrm{MVC}$ at

$2465 \min (p<.05)$, to $19.4 \%$ MVC at $10 \min (p<.05)$, to $22.6 \%$ MVC at $15 \min (p<.05)$,

247 and to $21.6 \% \mathrm{MVC}$ at $20 \mathrm{~min}(\mathrm{p}<.05)$. 
249 In muscle fatigue, there were general decreasing trends of the MPF with time. The 250 only significant changes were found when the load was $20 \%$ body weight. MPF at T1

251 significantly dropped to $85.8 \%$ at $10 \mathrm{~min}(p<.05)$, to $83.6 \%$ at $15 \min (p<.05)$ and to

$25283.9 \%$ at $20 \min (p<.05)$. At T4, MPF significantly dropped to $79.0 \%$ at $15 \min (p$

$253<.05)$ and to $77.9 \%$ at $20 \min (p<.05)$.

255 4. Discussion

257 There are two main types of electrodes used for electromyography (EMG) studies, the

258 fine electrode and the surface electrodes. Fine electrodes, also called fine-wire

259 electrodes, is a kind of invasive electrodes which are inserted to the muscle fibers

260 during EMG recording. The electrode placement often requires invasive procedure

261 performed by physician specialized in neurology. The procedure may introduce

262 discomfort or pain to the subject, and may also interfere with the human motion

263 analyzed. As the authors expected that there will be difficulties in recruiting children

264 subject for invasive EMG study, a non-invasive surface EMG protocol was employed

265 instead. Surface EMG is a safe and easy method commonly used in ergonomics and

266 biomechanics studies (De Luca, 1997). The most us eful applications of EMG are to 
267 estimate muscle activity and act as an index of muscle fatigue.

269 A treadmill was used as an experimental instrument in this study. It allowed control of

270 walking speed to facilitate removal of the effect introduced by different walking speed.

271 In this study, the subject walking speed was set at $1.1 \mathrm{~ms}^{-1}$, a comfortable speed of

272 walking for children (Hong and Brueggemann, 2000, Hong et al., 2000). Previous

273 studies showed significant differences between treadmill and floor walking on some

274 gait biomechanics measurements including double-limb support (Murray et al., 1985)

275 and knee motion (Strathy et al., 1983). However in general, Murray et al (Murray et al.,

276 1985) showed that treadmill walking does not differ from floor walking in EMG patterns

277 at slow $\left(0.80-0.83 \mathrm{~ms}^{-1}\right)$, free $\left(1.38-1.42 \mathrm{~ms}^{-1}\right)$ and fast speed $\left(1.92-1.93 \mathrm{~ms}^{-1}\right)$. As the

278 selected walking speed in this study lied between the ranges reported by Murray et al,

279 the results obtained from this study are likely to reflect the general tread of EMG

280 patterns in level ground walking.

282 Previous studies investigated EMG on different shoulder and trunk muscles in related

283 to load carriage by arms or backpack. In studying shoulder muscle fatigue during

284 prolonged arm elevation, Hagberg investigated the EMG of upper trapezius,

285 infraspinatus, deltoid and biceps brachialis muscles (Hagberg, 1981). In studying the 
muscle fatigue during load carriage in backpack, Bobet and Norman (1984) analyzed

287 the EMG of trapezius and erector spinae muscles. Cook and Neumann found that the

288 muscle activity decreased in lumbar paraspinal muscles when a load was carried in

289 backpack position when compared with a load anterior to the chest carried by arms

290 (1987). After reviewing the muscle selection in previous studies, upper trapezius,

291 lower trapezius and rectus abdominis were selected in this study.

292

293 The electrode placements were determined by an orthopaedics physician. As

294 backpack load is a symmetrical carriage method, electrodes were only attached to the

295 right side of the trunk in this study. An assumption was made that EMG patterns on

296 muscles on both side of the trunk were similar. The trapezius is the largest and most

297 superficial of the upper back muscle group, which is divided into upper, intermediate

298 and lower functional components. The origins of the lower trapezius are from the

299 spinous processes of the seventh cervical down to the twelfth thoracic vertebrae

300 (Wiater and Bigliani, 1999). Above the seventh cervical vertebrae, the upper trapezius

301 takes its origin from the ligamentum nuchae and as far superior as the external

302 occipital protuberance (Mercer and Bogduk, 2003). The upper trapezius inserts on the

303 posterior border of the lateral third of the clavicle, while the lower trapezius inserts on

304 the base of the spine of the scapula (Wiater and Bigliani, 1999). The orthopaedics 
305 physician first located the trapezius muscles origin border by palpation and then

306 identified the mid-point along this border. Then the orthopaedics physician palpated

307 the insertion position. Electrodes were attached at the middle position of the line

308 joining the mid-point of origin border and the insertion position. Rectus abdominis has

309 its origin at pubis crest and its insertion at xiphoid process and anterior ribs. The

310 orthopaedics physician again palpated the origin and insertion and determined the

311 mid-point in between, which was near the umbilicus position (Stokes et al., 1989).

312 Electrodes were attached at this mid-point.

314 Before each trial, the subjects were asked to take a 30-minute rest to remove muscle

315 fatigue. After the rest, the removal of any fatigue was confirmed by verbal feedback by

316 the subjects. There was no fatigue test, biomechanical or physiological, to determine if

317 the muscle was really free of fatigue at that moment. In reviewing the literature about

318 muscle fatigue studies, it was found that the researchers often just described that the

319 subjects have taken a certain period of resting time before the trial. Only verbal

320 feedback but no quantitative measurements were done to confirm this. Physiologically,

321 researchers may collect blood sample and check for the lactate (Douris, 1993) or

322 creatine phosphate concentration (Westerblad et al., 2002). Another method is

323 muscle biopsy analys is (Weston et al., 1999). However these methods are invasive 
324 and may cause wounds and bleeding to the subjects. As children subjects were

325 recruited in this study and they were less tolerant to invasive experiment procedure,

326 these methods were not employed. A 30-minute resting time plus a verbal feedback

327 was used to ensure the removal of fatigue before each trial.

329 Previous studies (Asmussen, 1979, Westerblad et al., 1998) showed that in muscle

330 fatigue, the decline of forces in muscle fibers showed a three-phase pattern, which

331 usually lasts for less than ten minutes. In the first phase, the force fell rapidly to about

$33280 \%$ of the initial. In the second phase, there was a relatively stable force production

333 period. In the last phase, the force dropped rapidly again. However, in some less

334 demanding exercise where fatigue developed more slowly, this three-phase pattern of

335 force decline was not observed. In other words, if such pattern was observed within

336 ten minutes, the exercise task could be too demanding physically (Vollestad et al., 337 1988).

339 In this study, a load of $15 \%$ bodyweight introduced significant increased activity in

340 lower trapezius, and a load of $20 \%$ bodyweight introduced significant increased

341 activity and muscle fatigue in both upper and lower trapezius (Figure 2). When the

342 load was $0 \%, 15 \%$ and $20 \%$, increased muscle activity was found at $20,15-20$, and 
$3435-20$ minutes respectively (Figure 3 ). When the load was $20 \%$, muscle fatigue was

344 found in upper trapezius and lower trapezius at the time point of 10 and 15 minutes

345 respectively (Figure 4 ). This indicated that a load of $20 \%$ resulted in a too demanding

346 task to the children participating in this study. Although loads of $0 \%$ and $15 \%$ also

347 introduced significant increase in muscle activity in lower trapezius, no muscle fatigue

348 was found within the 20 minutes walking time period.

350 Chansirinukor et al (2001) suggested that a $15 \%$ bodyweight load is too heavy to

351 maintain standing posture for adolescents. In level walking, other previous studies

352 suggested a $15 \%$ or $20 \%$ load introduced trunk forward lean (Hong and Brueggemann,

353 2000, Hong and Cheung, 2003, Li and Hong, 2004, Li et al., 2003) and increased

354 ventilation frequency (Li et al., 2003). A 10\% or more load introduced prolonged blood

355 pressure recovery time (Hong and Brueggemann, 2000, Hong et al., 2000) and

356 changes in gait kinematics and kinetics parameters (Chow et al., 2005). In stair

357 walking, a $10 \%$ or more load caused trunk inclination and increased plantar force

358 exertion in ascending stairs (Hong et al., 2003, Hong and Li, 2005). In general, these

359 studies suggested the limit of backpack load for children to be $10 \%$ body weight,

360 which is similar to the $10 \%-12 \%$ suggested weight recommended by Malhotra and

361 Sen Gupta in 1965 (Malhotra and Sen Gupta, 1965). From the results in this study, a 
$36215 \%$ load or more introduced significant increased muscle activity. However such

363 increase does not necessary mean any harmful effect to the children. A load of $20 \%$

364 load significant introduced muscle fatigue in upper trapezius in 10 minutes and in

365 lower trapezius in 15 minutes. No fatigue was found when the load was within $15 \%$

366 bodyweight. Therefore, a load within $15 \%$ of the body weight in a backpack was

367 determined to be an acceptable task to children aged six, if only muscle fatigue is to

368 be prevented. If the load is $20 \%$, the walking time should not exceed 5 minutes.

369

370 5. Conclusion

371

372 Overall results showed that a $15 \%$ body weight load significantly increased muscle

373 activity at upper trapezius and a $20 \%$ load significantly increased muscle activities at

374 both upper and lower trapezius. In prolonged walking, a 15\% load significantly

375 increased muscle activity at lower trapezius from 15 minutes, and a $20 \%$ load

376 significantly increased it from 5 minutes. When walking with a $20 \%$ load, muscle

377 fatigue was found at upper trapezius from 10 minutes and at lower trapezius from 15

378 minutes. No increased muscle activity or muscle fatigue was found in rectus

379 abdominis within the $20 \%$ load range and 20 minutes walking period. 
381 It is suggested that for children aged six to walk within 20 minutes, while carrying load

382 of $15 \%$ of body weight, no muscle fatigue on upper trapezius, lower trapezius and 383 rectus abdominis could occur.

384

385 References:

1. Asmussen E. Muscle fatigue. Medicine and Science in Sports. 1979;11(4):313-321.

2. Bjelle A, Hagberg M, Michaelson G. Occupational and individual factors in Ind ustrial Medicine. 1981;38(4):356-363.

3. Bobet J, Norman RW. Effects of load placement on back muscle activity in load carriage. European Journal of Applied Physiology and Occupational Physiology.

4. Bobet J, Norman RW. Use of the average electromyogram in design evaluation. Investigation of a whole-body task. Ergonomics. 1982;25(12):1155-1163.

5. Boone KG, Holder DS. Effect of skin impedance on image quality and variability in electrical impedance tomography: a model study. Medical and Biological Engineering and Computing. 1996;34(5):351-354. 
shoulder joint position sense. American Journal of Sports Medicine. $1998 ; 26(2): 262-265$.

402 7. Chansirinukor W, Wilson D, Grimmer K, Dansie B. Effects of backpacks on students: measurement of cervical and shoulder posture. Australian Journal of

8. Charteris J. Comparison of the effects of backpack loading and of walking speed on foot-floor contact patterns. Ergonomics. 1998;41(12):1792-1809.

9. Chow DHK, Kwok MLY, Au-Yang ACK, Holmes AD, Cheng JCY, Yao FYD, Wong MS. The effect of backpack load on the gait of normal adolescent girls.

10. Cook TM, Neumann DA. The effects of load placement on the EMG activity of Ergonomics . $2005 ; 48(6): 642-656$.

11. De Luca CJ. The use of surface electromyography in biomechanics. Journal of Applied Biomechanics. 1997;13(2):135-163.

12. Douris PC. The effect of isokinetic exercise on the relationship between blood lactate and muscle fatigue. Journal of Orthopaedic and Sports Physical Therapy. 1993;17(1):31-35.

418 13. Gribble PA, Hertel J. Effect of lower-extremity muscle fatigue on postural 
14. Grimmer KA, Williams MT, Gill TK. The associations between adolescent head-on-neck posture, backpack weight, and anthropometric features. Spine.

15. Hagberg M. Electromyographic signs of shoulder muscular fatigue in two $1999 ; 24(21): 2262-2267$.

16. Hodges PW, Richardson CA. Inefficient muscular stabilization of the lumbar spine associated with low back pain. A motor control evaluation of transversus abdominis. Spine. 1996;21(22):2640-2650.

17. Hong Y, Brueggemann GP. Changes in gait patterns in 10 -year-old boys with increasing loads when walking on a treadmill. Gait and Posture.

18. Hong Y, Cheung CK. Gait and posture responses to backpack load during level walking in children. Gait and Posture. 2003;17(1):28-33.

19. Hong Y, Lau TC, Li JX. Effects of loads and carrying methods of school bags on movement kinematics of children during stair walking. Research in Sports

20. Hong Y, Li JX. Influence of load and carrying methods on gait phase and 
ground reactions in children's stair walking. Gait and Posture. Aug $2005 ; 22(1): 63-68$.

21. Hong Y, Li JX, Wong AS, et al. Effects of load carriage on heart rate, blood pressure and energy expenditure in children. Ergonomics. 2000;43(6):717-727.

22. Hong Kong Society for Child Health and Development, The Department of

25. Lai JP, Jones AY. The effect of shoulder-girdle loading by a school bag on lung volumes in Chinese primary school children. Early Human Development. $2001 ; 62(1): 79-86$.

26. Li JX, Hong Y. Age difference in trunk kinematics during walking with different backpack weights in 6- to 12-year-old children. Research in Sports Medicine. $2004 ; 12(2): 135-142$. 
457 27. Li JX, Hong Y, Robinson PD. The effect of load carriage on movement $458 \quad$ kinematics and respiratory parameters in children during walking. European 459 Journal of Applied Physiology. 2003;90(1-2):35-43.

460 28. Malhotra M, Sen Gupta J. Carrying of school bags by children. Ergonomics. 1965;8(1-4):55-60 .

29. Mercer SR, Bogduk N. Clinical anatomy of ligamentum nuchae. Clinical Anatomy. 2003;16(6):484-493.

30. Murray MP, Spurr GB, Sepic SB, Gardner GM, Molinger LA. Treadmill vs. floor walking: kinematics, electromyogram, and heart rate. Journal of Applied Physiology. 1985;59(1):87-91.

31. Negrini S, Carabalona R. Backpacks on! Schoolchildren's perceptions of load, 2002;27(2):187-195.

32. Pascoe DD, Pascoe DE, Wang YT, Shim DM, Kim CK. Influence of carrying book bags on gait cycle and posture of youths. Ergonomics.

33. Sheir-Neiss GI, Kruse RW, Rahman T, Jacobson LP, Pelli JA. The association of backpack use and back pain in adolescents. Spine. 2003;28(9):922-930.

475 34. Stokes IA, Moffroid M, Rush S, Haugh LD. EMG to torque relationship in rectus 
abdominis muscle. Results with repeated testing. Spine. 1989;14(8):857-861.

477 35. Strathy GM, Chao EY, Laughman RK. Changes in knee function associated with treadmill ambulation. Journal of Biomechanics. 1983;16(7):517-522.

38. Vollestad NK. Measurement of human muscle fatigue. Journal of Neuroscience muscle fatigue on and the relationship of arm dominance to shoulder proprioception. Journal of Orthopaedic and Sports Physical Therapy. $1996 ; 23(6): 348-352$.

37. Voll HJ, Klimt F. Strain in children caused by carrying school bags. Offentliche Gesundheitswesen. 1977;39:369-378. Methods. 1997;74(2):219-227.

39. Vollestad NK, Sejersted OM, Bahr R, Woods JJ, Bigland-Ritchie B. Motor drive and metabolic responses during repeated submaximal contractions in humans. Journal of Applied Physiology. 1988;64(4):1421-1427.

40. Westerblad H, Allen DG, Bruton JD, Andrade FH, Lannergren J. Mechanisms underlying the reduction of isometric force in skeletal muscle fatigue. Acta Physiologica Scandinavica. 1998;162(3):253-260.

41. Westerblad H, Allen DG, Lannergren J. Muscle fatigue: lactic acid or inorganic phosphate the major cause? News in Physiological Sciences. 
496 42. Weston AR, Karamizrak O, Smith A, Noakes RD, Myburgh KH. African runners exhibit greater fatigue resistance, lower lactate accumulation, and higher oxidative enzyme activity. Journal of Applied Physiology. 1999;86(3):915-923.

43. Wiater JM, Bigliani LU. Spinal accessory nerve injury. Clinical Orthopaedics

44. Yang JF, Winter DA. Electromyographic amplitude normalization methods: improving their sensitivity as diagnostic tools in gait analysis. Archives of Physical Medicine and Rehabilitation. 1984;65(9):517-521. 
Figure 1 - Subject performing treadmill walking test with electrodes attached on upper trapezius, lower trapezius and rectus abdominis

Figure 2 - IEMG and MPF of each muscle at each load (load effect)

Figure 3- IEMG of each muscle at each load and time point (time effect on each load)

Figure 4-MPF of each muscle at each load and time point (time effect on each load) 
Figure 2

Click here to download high resolution image
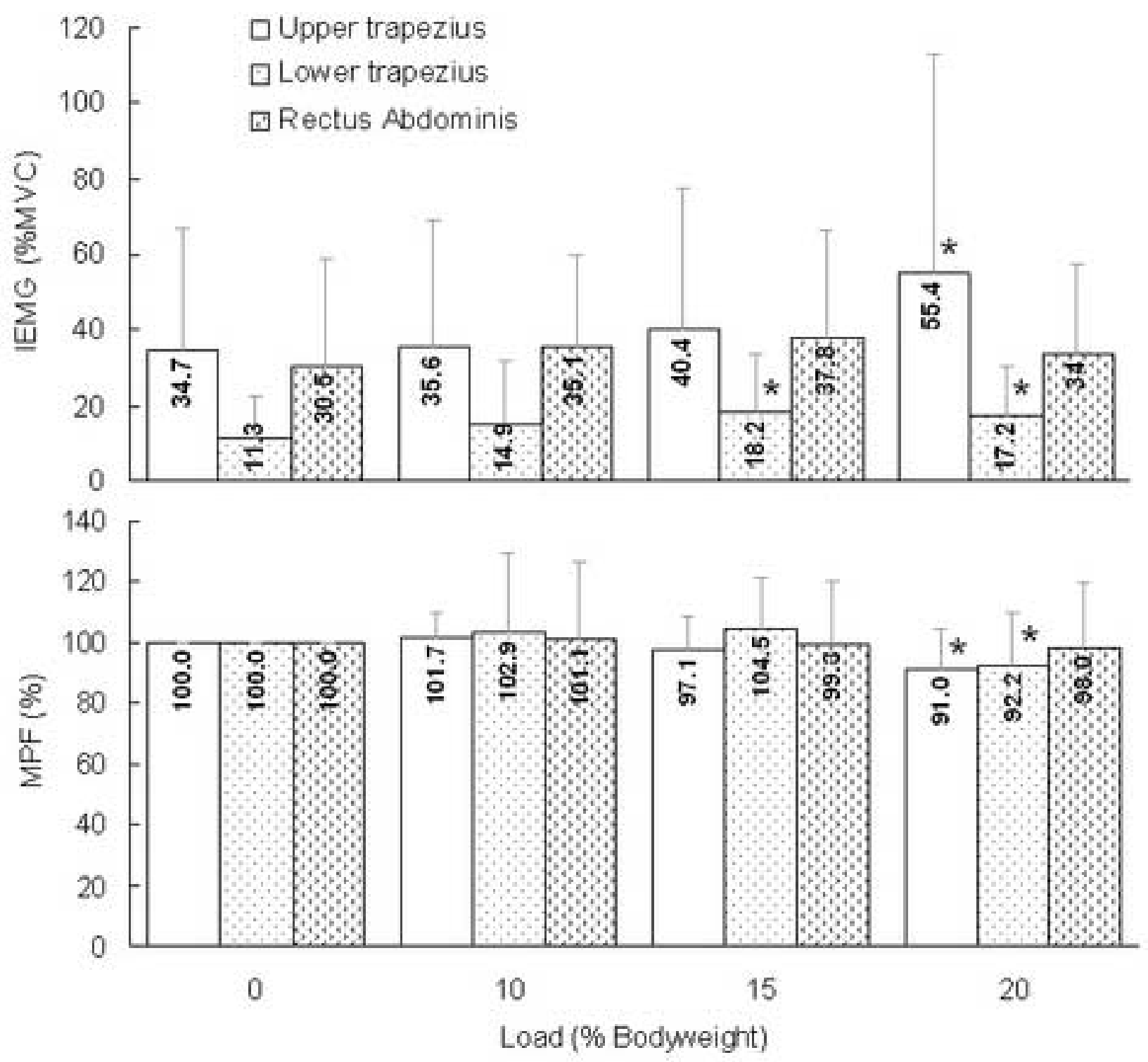


\section{Figure}

Click here to download high resolution image
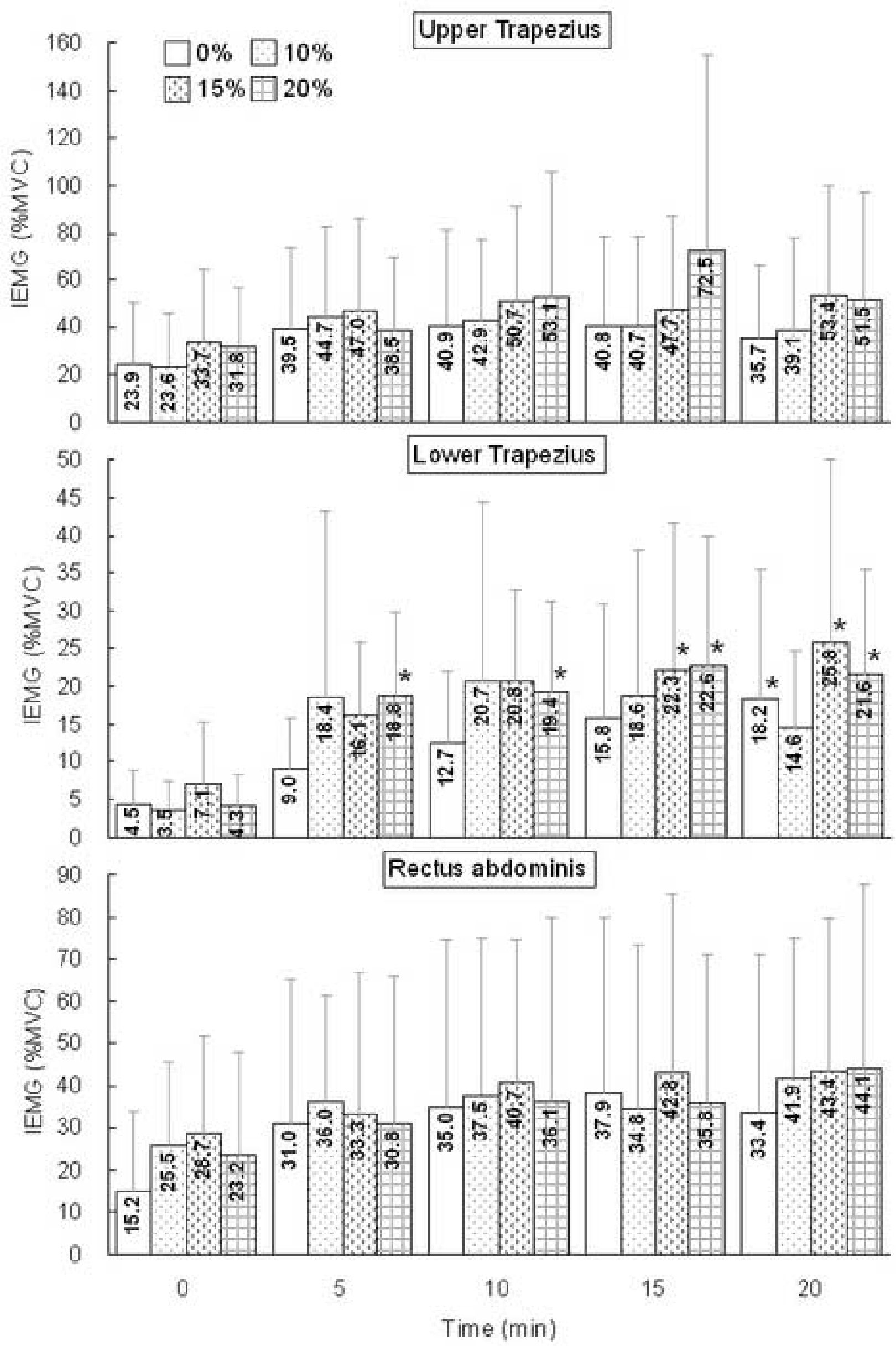

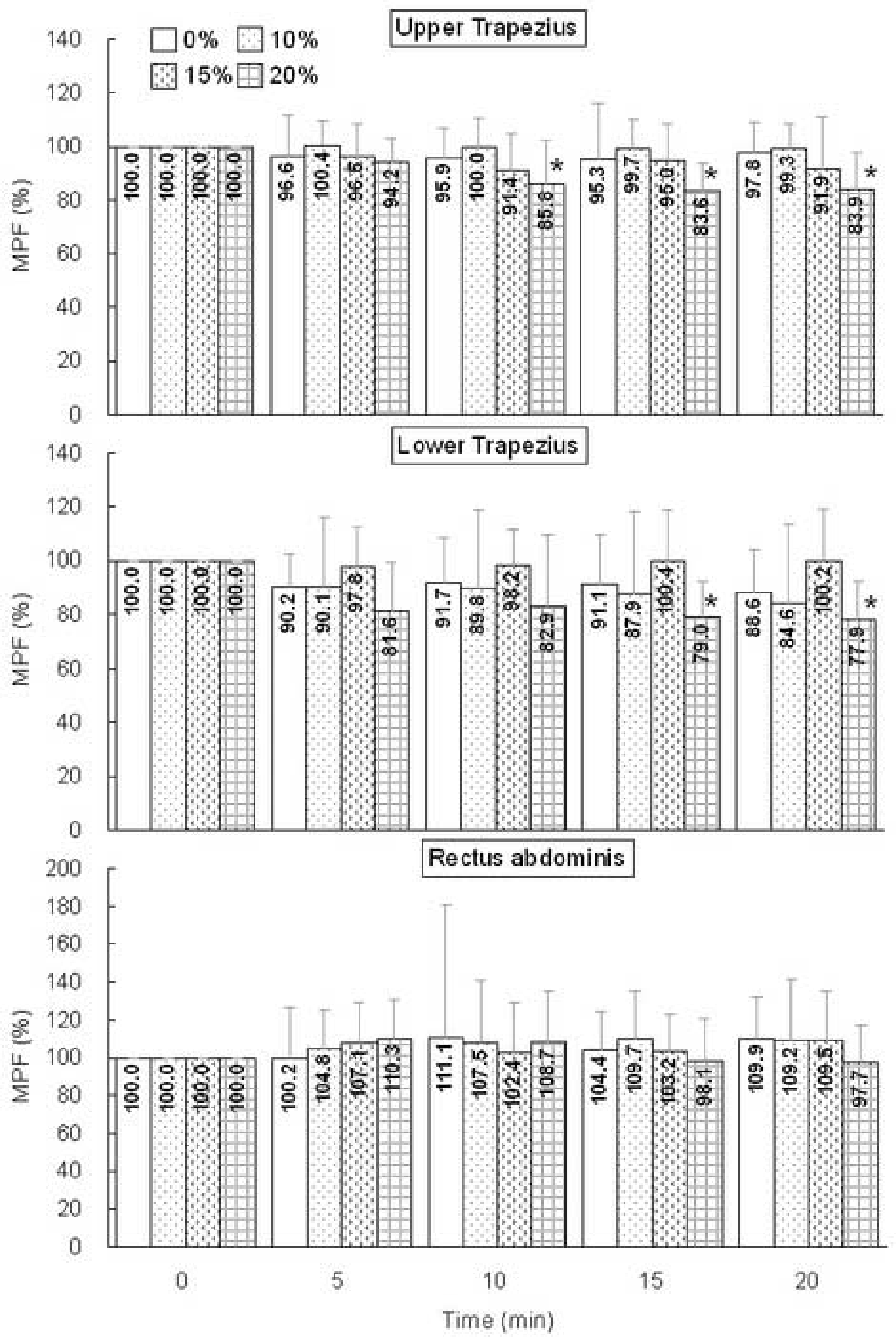